\title{
A CLINICOPATHOLOGICAL STUDY OF CUTANEOUS GRANULOMA
}

Bornali Dutta1', Rajib Ray Baruah², Mohammad Muidul Huda3, Bijoy Chandra Gogoi ${ }^{4}$, Anjali Dutta ${ }^{5}$

${ }^{1}$ Assistant Professor, Department of Dermatology \& Venereology, FAAMC\&H, Assam.

${ }^{2}$ Assistant Professor, Department of Paediatric Surgery, GMC\&H, Assam.

${ }^{3}$ Retd. Professor and HOD, Department of Dermatology \& Venereology, AMC\&H, Assam.

${ }^{4}$ Retd. Professor and HOD, Department of Pathology AMC\&H, Assam.

${ }^{5}$ Retd. Professor, Department of Pathology, AMC\&H, Assam.

\section{ABSTRACT}

\section{BACKGROUND}

A wide range of immunologic and non-immunologic causes can lead to the formation of a granuloma. The aetiological agent and immunological status of the host determines the clinical presentation of these chronic skin lesions. However, diagnosis often becomes intricate as different clinical types present with morphological similarities, which gets further complicated by time and presumptive therapy.

\section{AIMS}

To study the incidence and clinical pattern of cutaneous granulomas; their relationship with age, sex, trauma and determine the importance of laboratory tests, specially histopathology in confirming aetiological diagnosis.

\section{SETTINGS AND DESIGN}

Cross-sectional study, based on hospital records.

\section{METHODS AND MATERIAL}

The study was from OPD records of Department of Dermatology and Venereology. All patients who had attended with clinically suspected cutaneous granulomatous lesions and underwent investigative procedures over a one-year period were included in the study. The relevance of the investigative procedures used, especially histopathology in arriving at the final diagnosis was established. Statistical analysis used: Descriptive statistical analysis and Chi-square test whenever appropriate.

\section{RESULTS AND CONCLUSIONS}

A total of 300 cases of cutaneous granuloma were included in the study. There was a male preponderance. The commonest cutaneous granuloma encountered was leprosy followed by fungal and tubercular granuloma. Less frequently encountered forms were syphilis, foreign body, parasitic, lymphogranuloma venereum, actinomycosis, rhinoscleroma, donovanosis and granulomatous mycosis fungoides. A total of $83.39 \%$ cases showed clinic-histopathological correlation. Cutaneous granulomas cause diagnostic difficulty due to clinical diversity and mimicry. Cutaneous granulomas of similar origin can present with varied clinical presentations, while those from different backgrounds can have similar presentations. A histopathological examination continues to be highly contributory in confirming the aetiological diagnosis with proper clinical correlation.

\section{KEYWORDS}

Granuloma, Histopathology, Cutaneous.

HOW TO CITE THIS ARTICLE: Dutta B, Baruah RR, Huda MM, et al. A clinicopathological study of cutaneous granuloma. J. Evolution Med. Dent. Sci. 2016;5(22):1184-1189, DOI: 10.14260/jemds/2016/275

\section{INTRODUCTION}

Granulomas form as a response to insoluble, non-degradable, or slowly released antigens, which cause transformation of histiocytes into activated macrophages, epithelioid cells and multinucleated giant cells. There are two types of granulomas which differ in their pathogenesis; foreign body and immune granulomas. Foreign body granulomas are formed around inert foreign bodies without $\mathrm{T}$-cell mediated immune responses. Immune granulomas are caused by a variety of agents like persistent microbes or self-antigens, which induce a persistent $\mathrm{T}$-cell mediated immune response. ${ }^{1}$ In clinical practice, foreign body granulomas and immune granulomas of infective origin are mostly encountered.

Financial or Other, Competing Interest: None.

Submission 20-01-2016, Peer Review 29-02-2016,

Acceptance 05-03-2016, Published 17-03-2016.

Corresponding Author:

Dr. Bornali Dutta

C1, Krishna Cauvery Enclave,

D Neog Path, Behind Dona Planet, ABC,

Guwahati-781005, Assam.

E-mail: dr.bornali.dutta@gmail.com

DOI: $10.14260 /$ jemds $/ 2016 / 275$
Granulomas from different agents often share clinical similarities and histology also often creates a picture of ambiguity. In such situations, a co-ordination between the dermatologist and pathologist becomes mandatory.

The study was undertaken to study the incidence and varied clinical manifestations of various cutaneous granulomas, to correlate the clinical and laboratory findings, mainly histopathology, in establishing clinicopathological concordance and confirming aetiological diagnosis. An attempt was also made to compare the efficacy of diagnostic strategies used with other studies.

\section{MATERIALS AND METHODS}

This cross-sectional study based on hospital records was done in the Dermatology and Venereology Department of a tertiary care hospital. Proper permission was taken from hospital authorities for use of data for research purpose; any identification data was duly removed. A period of one year was chosen for operational feasibility as collected hospital records had to be analysed and some data needed to be corroborated with the results in the Department of Pathology. The number of cases collected over this period also seemed adequate for 
the study. Data was included in a specially prepared proforma for the study and subjected to statistical analysis. Photographs and photomicrographs used were available with the authors.

- Statistical methods used were descriptive statistics and Chi squared tests were done whenever appropriate for drawing inference.

\section{Inclusion Criteria}

- $\quad$ Patient's presenting with chronic (More than six weeks) skin lesions.

- Lesions comprising of indurated nodules, noduloulcerative lesions, papules, sinuses with or without scarring, non-healing ulcers, verrucous and hypertrophied plaques, vascular mass with induration and manifesting two out of three cardinal signs of leprosy.

- Patients who had undergone mandatory investigations like blood haemogram, routine examination of urine and stool, blood biochemistry, biopsy and histopathological examination (Except the cases of syphilis as serological tests are considered confirmatory for diagnosis).

- Patients who had undergone special investigations like direct microscopy for fungal elements, slit skin smear, Mantoux test, Dark Ground Illumination (DGI) tests, serological tests for syphilis and fungal culture in Sabouraud's Dextrose Agar whenever indicated. Special stains like Gram's, Giemsa, Periodic Acid Schiff (PAS), Lactophenol Blue and Ziehl Neelsen complemented the above tests.

\section{Exclusion Criteria}

- Those who had not undergone the mandatory tests, except the cases of syphilis.

- $\quad$ Cases with incomplete data.

\section{RESULTS}

Out of a total of 14,164 cases seen in the Dermatology OPD in the study period, number of cases presenting with cutaneous granuloma was $300(2.11 \%)$. The commonest cutaneous granuloma encountered was leprosy $(69.33 \%)$ followed by fungal $(11.33 \%)$ and tubercular (8\%) granuloma. Syphilis along with other less frequently diagnosed granulomas accounted for $1.34 \%$ of cases (Fig. 1).

Maximum cases were from the 20-29 years age group; youngest was a case of BCG granuloma, 6 months of age. (Fig. 2). There was a definite male preponderance of $72.33 \%$. Patients from urban background outnumbered rural 2.06:1. History of trauma was elicited in 38 patients (24 males, 14 females) presenting with fungal and tubercular granulomas. The site most commonly affected was the upper extremity (30.36\%) followed by lower extremity (29.68\%), trunk including genitalia and lymph nodes $(22.09 \%)$ and scalp, face and neck including lymph nodes $(17.86 \%)$.

Out of 208 clinically diagnosed cases of leprosy, clinical features of tuberculoid leprosy (TT) were seen in 20 (9.6\%), borderline tuberculoid (BT) in 99 (47.6\%), mid borderline (BB) in 25 (12.0\%), borderline lepromatous (BL) in 28 $(13.5 \%)$ and lepromatous leprosy (LL) in 36 (17.3\%) including $4(1.92 \%)$ cases of histoid leprosy. Smear positivity for Acid Fast Bacilli (AFB) was found in 25.96\%. A total of 174 (83.7\%) cases showed evidence of leprosy on Histopathological Examination (HPE); of these clinical and histopathological correlation was found in 124 (59.6\%). The clinicopathological concordance among the various subtypes of leprosy was significant with a $\mathrm{p}$ value of 0.008 , Chi-square value $=18.900$ and $\mathrm{df}=4$ (Table 1$)$.

Fungal granulomas accounted for 34 (11.33\%) cases, of which 25 (73.5\%) were sporotrichosis, 4 (11.76\%) chromoblastomycosis (Fig. 3), 3 (8.82\%) mycetoma and $1(2.94 \%)$ each of rhinosporidiosis and candida granuloma. Histological evaluation showed definite evidence of fungal granuloma in 26 (76.47\%), non-specific changes in $6(17.64 \%)$ and $1(2.94 \%)$ showed a picture consistent with tubercular granuloma. No specific organism or asteroid bodies were seen in any of the cases of sporotrichosis; characteristic muriform or sclerotic bodies (Fig. 4) could be seen in all 4 cases of chromoblastomycosis, grains with multiple small abscesses (Fig. 5) were seen in 2 out of 3 cases of mycetoma and the single case of rhinosporidiosis (Fig. 6) showed multiple sporangia in different stages of development (Fig. 6, 7). A total of $25(73.53 \%)$ cases confirmed a growth consistent with the causative organism when subject to mycological culture.

The next group was tubercular granulomas. Out of the 24 clinically diagnosed cases, clinical features of lupus vulgaris (Including one case of BCG granuloma) was seen in maximum number of 12 (50\%), scrofuloderma in 10 (41.7\%), tuberculosis verrucosa cutis in $2(8.3 \%)$ cases. Biopsy and HPE showed definite evidence of tubercular granuloma in 22 (91.67\%) cases; 11 (91.67\%) of lupus vulgaris, all cases of scrofuloderma and 1 (50\%) case of tuberculosis verrucosa cutis. A single case of scrofuloderma showed presence of bacilli. Mantoux positivity was seen in 20 (83.33\%) cases.

Primary and secondary syphilis accounted for 17 cases. Dark Ground Illumination (DGI) was found to be positive in 13 (76.47\%) cases. Serological tests showed 100\% positivity. Biopsy and HPE were not available.

Four patients diagnosed clinically as foreign body granulomas, presenting with indolent, asymptomatic nodules over different areas of the body like breast (Scar), forehead, forearm with antihelix and lower leg were biopsied. Excision biopsy and HPE showed pictures of a suture granuloma, silica granuloma, ruptured sebaceous cyst and gouty tophi with granulomatous reaction (Fig. 8), showing 100\% concordance. Parasitic granuloma was clinically considered from the history and site of presentation in 3 patients, viz. nodules over forehead in one; abdomen, ear and arm in another; and scrotal enlargement with discharging sinus in the third. Histopathological examination was consistent with our clinical diagnosis in all 3 (100\%) cases; bodies of cysticerci (Fig. 9) and microfilaria (Fig. 10) with granulomatous reaction were established in 2 and 1 case respectively.

Three cases were clinically suspected to be suffering from Lymphogranuloma Venereum (LGV); two cases presented with bubo, 1 with genital elephantiasis. Lymph node biopsy showed consistent findings in $2(66.67 \%)$ patients (Fig. 11).

Rhinoscleroma involving the nose was the clinical diagnosis in 2 cases, which gave consistent findings on histology (100\%). Donovanosis was clinically suspected in 2 cases, presenting as granulomatous ulcers over genitalia; diagnosis was established in one case $(50 \%)$ through tissue smear and HPE. The other case showed features of nonkeratinizing type of squamous cell carcinoma. Two cases were 
clinically diagnosed as actinomycosis from lesions over maxillary and mandibular regions.

HPE gave consistent findings in one case (50\%). Features of granulomatous mycosis fungoides was found on HPE of noduloulcerative lesions on face of an old man presenting with similar lesions over the face, trunk, upper extremities showing $100 \%$ clinicopathological concordance.

Out of the 283 cases that underwent biopsy and histopathological examination, 236 cases showed positive results accounting for $83.39 \%$. Seventeen cases that did not undergo biopsy were clinically suspected cases of syphilis where serology and bacteriological study were considered confirmatory for clinical purpose (Table 2).

\begin{tabular}{|c|c|c|c|}
\hline & \multicolumn{2}{|c|}{$\begin{array}{c}\text { Histopathological } \\
\text { Confirmation (Numbers) }\end{array}$} & P value \\
\hline $\begin{array}{c}\text { Clinical } \\
\text { Types }\end{array}$ & Yes & No & \multirow{6}{*}{$\begin{array}{c}0=18.900 \\
\mathrm{df}=4 \\
\mathrm{p} \text { value }= \\
0.008\end{array}$} \\
\hline TT & 20 & 10 & \\
\hline BT & 59 & 40 & \\
\hline $\mathrm{BB}$ & 15 & 10 & \\
\hline $\mathrm{BL}$ & 12 & 16 & \\
\hline LL & 28 & 08 & \\
\hline Table & $\begin{array}{l}\text { owing } \\
\text { of th }\end{array}$ & $\begin{array}{l}\text { Histolo } \\
\text { es of Ley }\end{array}$ & correlation \\
\hline
\end{tabular}

\begin{tabular}{|c|c|c|c|}
\hline & $\begin{array}{r}\text { Hist } \\
\text { Confi } \\
(\mathrm{Nu}\end{array}$ & $\begin{array}{l}\text { ical } \\
\text { tion } \\
\text { er) }\end{array}$ & P value \\
\hline Clinical Types & Yes & No & \multirow{7}{*}{$\begin{array}{c}\text { Chi squared } \\
\text { test } \\
\text { was not } \\
\text { done as } \\
\text { some of the } \\
\text { expected } \\
\text { values } \\
\text { were less } \\
\text { than } 5\end{array}$} \\
\hline Leprosy & 174 & 34 & \\
\hline Fungal granuloma & 26 & 8 & \\
\hline Tubercular granuloma & 22 & 2 & \\
\hline Foreign body granuloma & 22 & 2 & \\
\hline Parasitic granuloma & 4 & 0 & \\
\hline $\begin{array}{l}\text { Lymphogranuloma } \\
\text { venereum }\end{array}$ & 3 & 0 & \\
\hline Actinomycosis & 2 & 1 & \\
\hline Rhinoscleroma & 2 & 0 & \\
\hline Donovanosis & 1 & 1 & \\
\hline $\begin{array}{l}\text { Granulomatous mycosis } \\
\text { fungoides }\end{array}$ & 1 & 0 & \\
\hline \multicolumn{4}{|c|}{$\begin{array}{l}\text { Table 2: Showing overall Clinicohistopathological } \\
\text { correlation of Cutaneous Granulomas }\end{array}$} \\
\hline
\end{tabular}

Syphilis was not included in the table as biopsy and histopathological tests were not done.

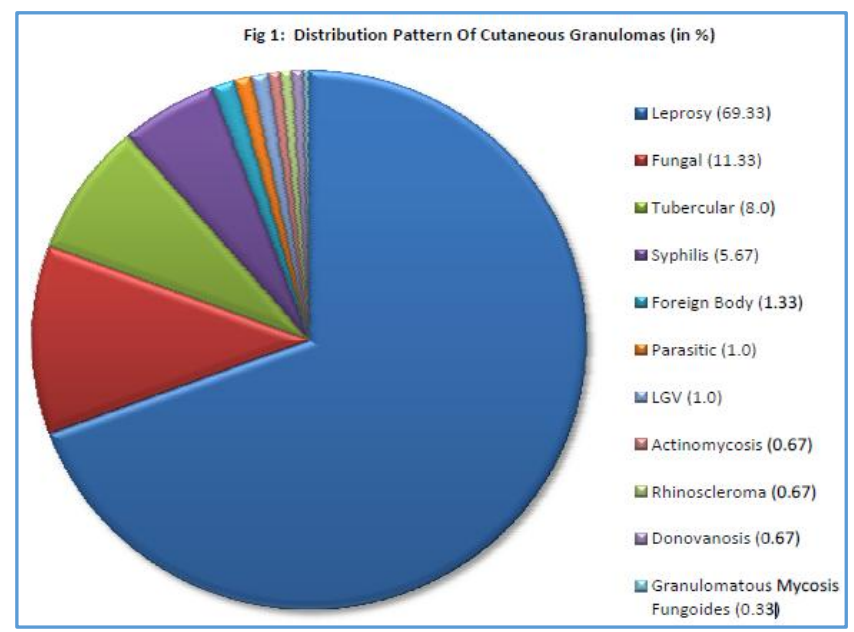

Fig. 1: Distribution pattern of Cutaneous Granulomas: Granulomas (In percentage)

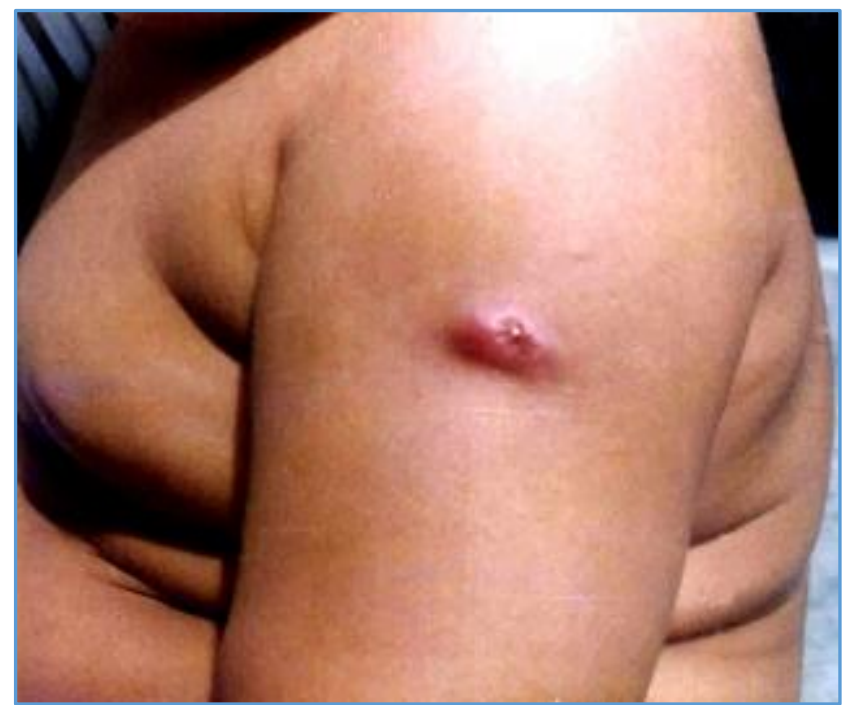

Fig. 2: Photograph of the arm of an infant showing BCG Granuloma

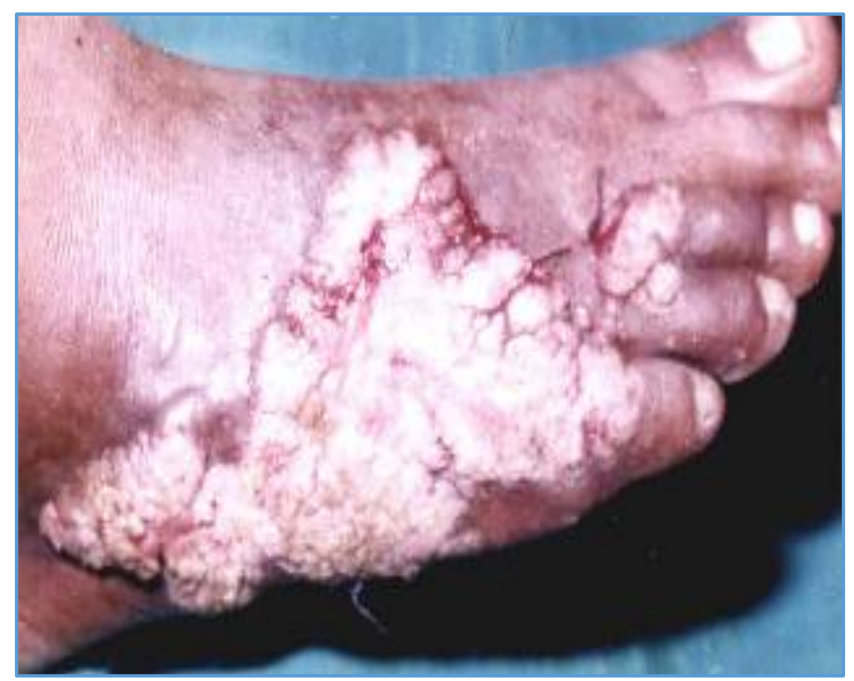

Fig. 3: Photograph of a case of Chromoblastomycosis with Hypertrophied Plaques on the right foot

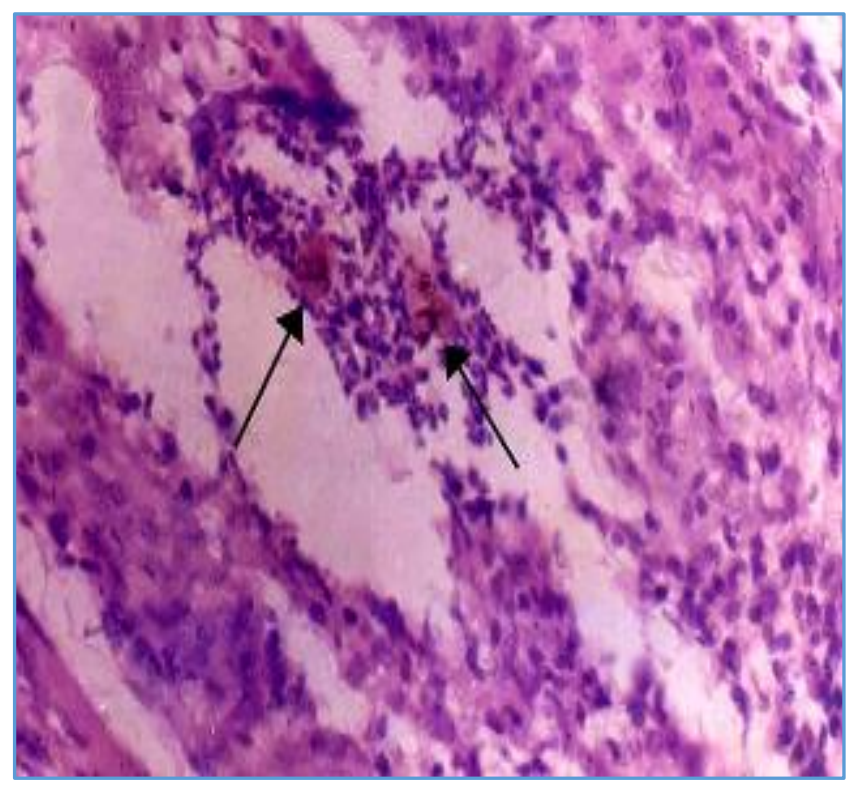

Fig. 4: Photomicrograph of a case of Chromoblastomycosis showing characteristic Muriform or Sclerotic cells in Necrotic Tissue (H\&E X 250) 


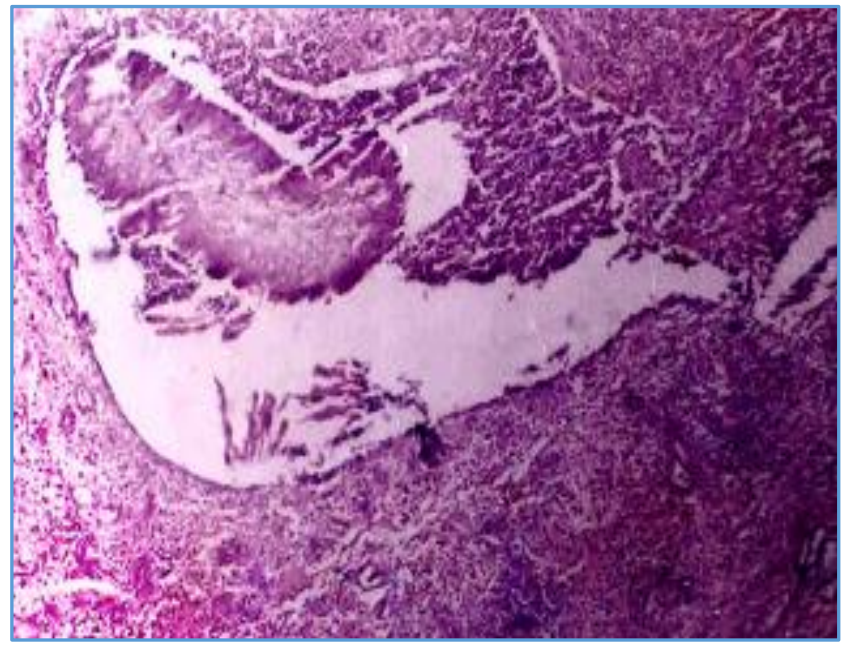

Fig. 5: Photomicrograph showing Grains of Mycetoma (H\&E X 150)

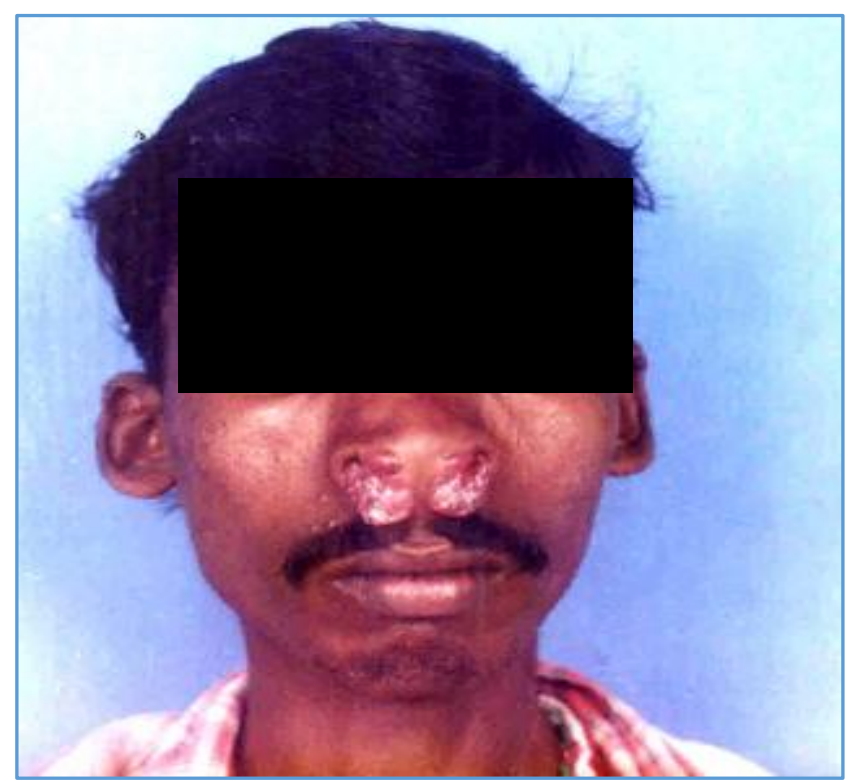

Fig. 6: Photograph of a case of rhinosporidiosis with polypoidal lesions over nasal mucosa. Surface is studded with multiple white spots

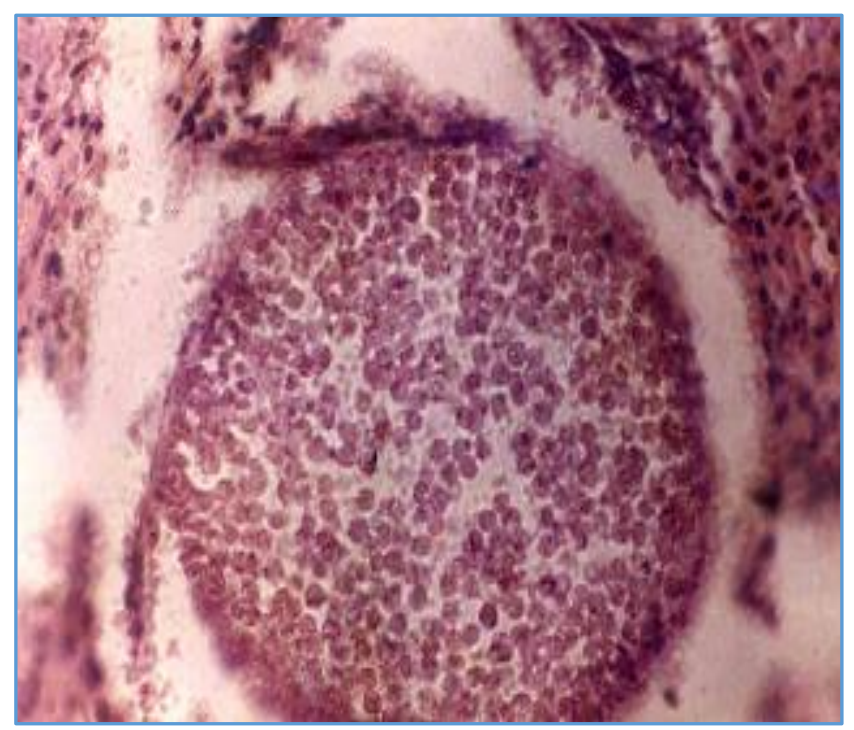

Fig. 7: Photomicrograph showing sporangium of rhinosporidiosis (H\&E X 250)

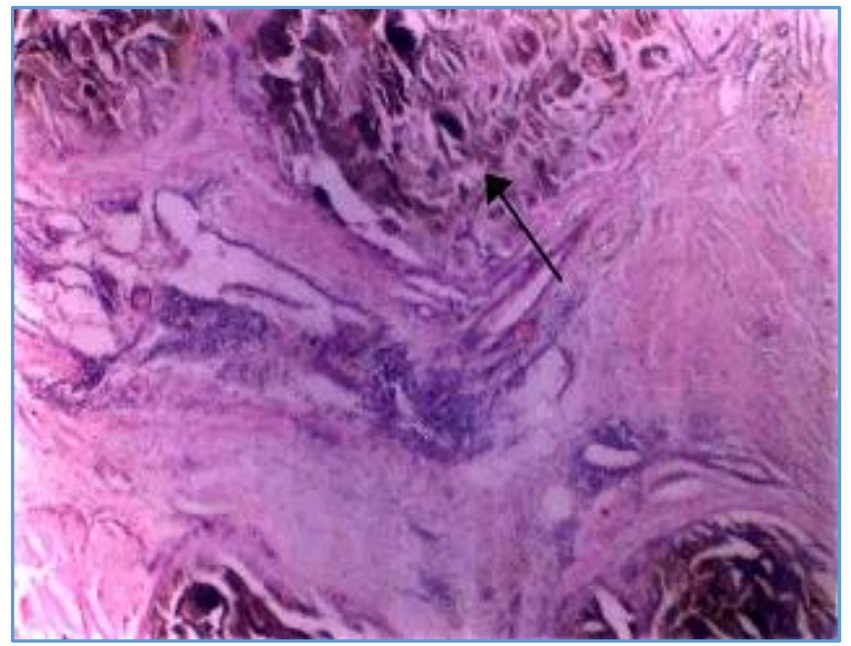

Fig. 8: Photomicrograph showing Gouty Tophi with Foreign Body Granulomatous Reaction (H\&E X 250)

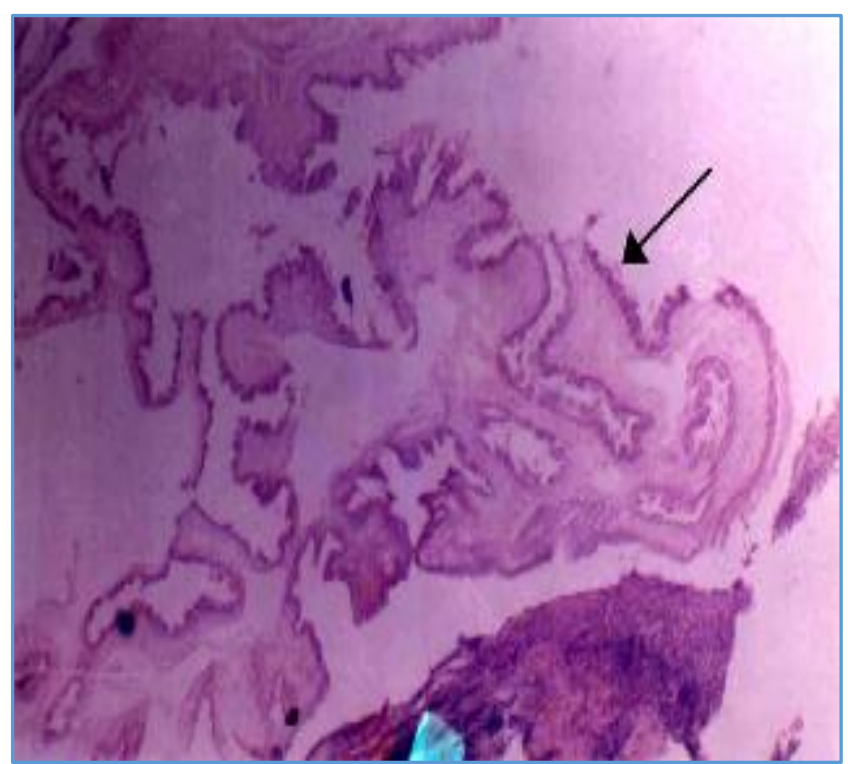

Fig. 9: Photomicrograph showing Body of Cysticercus Cellulosae (shown by arrow) with Granulomatous Reaction (H\&E X 250)

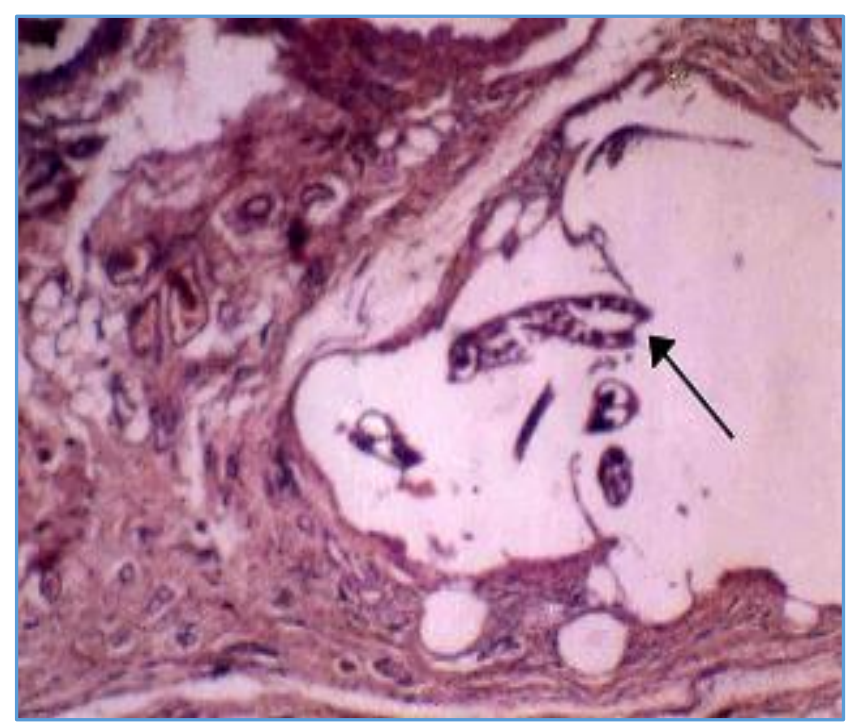

Fig. 10: Photomicrograph showing Microfilaria (Shown by arrow) with Granulomatous Reaction (H\&E X 250) 


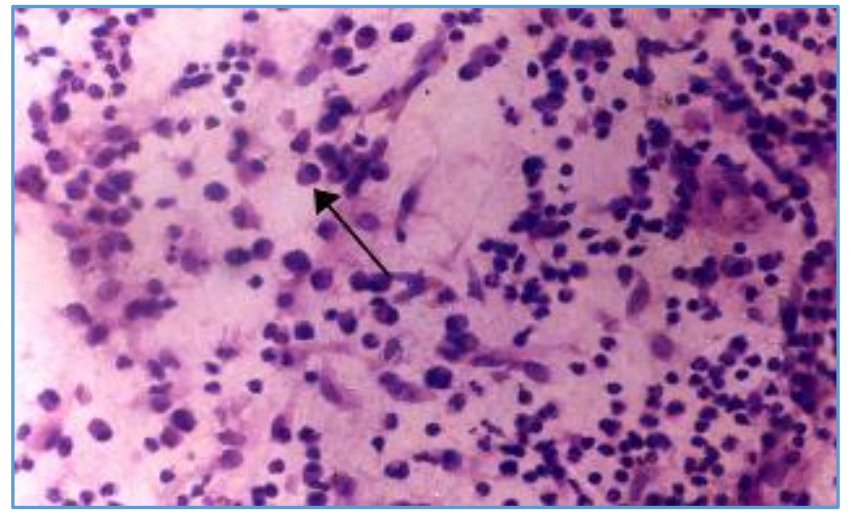

Fig. 11: Photomicrograph showing Histopathological appearance of Lymphogranuloma Venereum with abundant Plasma Cells (H\&E X 250)

\section{COMMENTS}

The commonest cutaneous granuloma in our study was leprosy followed by fungal granuloma, tubercular granuloma and others amounting to an OPD attendance of $2.11 \%$. Our study is very similar to a study by Permi et al. where maximum number of cases was of tuberculosis followed by leprosy and other granulomas accounting for $2.1 \%{ }^{2}$

Males outnumbered females in our study with a ratio of 2.6:1 comparable with most studies, while it differed from observations by Zafar et al. The maximum number of cases was seen in 20 to 29 years' age group, which is in conformity to studies by other authors. ${ }^{2-4}$

The highest number of cases with cutaneous granuloma was leprosy accounting for 208 (69.33\%) cases. Leprosy was the commonest clinical type in most studies, while tuberculosis formed the commonest group in few others. ${ }^{2-7}$ The highest number of cases was seen in the Borderline group amounting to 152 (73.08\%) cases, which are in agreement with few and differed from other studies where TT and LL were the common types. Histopathological examination of all biopsies showed definite evidence of leprosy in 174 (83.7\%) cases, correlation was found in 124 (59.6\%), which is similar to earlier studies by workers where it ranged from 33.75 to $80.4 \%$.

The maximum concordance was observed in the LL group (77-78\%), which is similar to studies by various workers where parity with LL ranged from $75.86 \%$ to $95.2 \%$ respectively. This reiterates the fact that maximum parity is observed in the polar group, as they are stable and show a fixed histopathology.6,8 Concordance observed in the borderline group was $56.58 \%$. Many observers have found minimum concordance in borderline groups, probably because of variable lesions with variable histology in the same patient. The low parity in the TT group in our study disagrees with other workers and could be due to incorrect clinical assessment. Acid fast bacilli were demonstrated in $25.9 \%$; it has varied from $25.72 \%$ to $44.6 \%$ in various studies. ${ }^{9}$

The highest number of cases of fungal granuloma comprised of sporotrichosis (73.5\%), followed by chromoblastomycosis, mycetoma, rhinosporidiosis and candida granuloma. The pattern is different from studies by workers in Singapore and Mangalore, where commonest types were mycetoma and aspergillus respectively, while it is similar to a recent study from the same part of the country. The relative difference in our clinical pattern from the earlier studies is probably due to the significantly different geographical location and governing diverse conditions of temperature and humidity.2,10 Concordance between clinical and histopathological diagnosis for the fungal granulomas was $26(76.46 \%)$ showing the following pattern; sporotrichosis $72 \%$, chromoblastomycosis $100 \%$, mycetoma $66.6 \%$, rhinosporidiosis $100 \%$ and candida granuloma $100 \%$. Out of all the cases subject to fungal culture, consistent growth was confirmed with $25(73.53 \%)$ with sporotrichosis showing $76 \%$, chromoblastomycosis $75 \%$, mycetoma $66.67 \%$ and candida $100 \%$ positivity.

Rhinosporidiosis did not show any growth. A disparity may occur between fungal culture and histology in situations where tissue set for culture does not contain viable fungus, has been ground too aggressively and has been sampled from two different areas. ${ }^{11}$ Direct microscopy from crusts and scraping was positive in $2(50 \%)$ cases of chromoblastomycosis and one case of candida. One case of mycetoma showed thick hyphae of eumycetoma, while neither yeast like cells or asteroid bodies were seen in sporotrichosis which is similar to other studies, possibly due to the paucity of yeasts in tissues. ${ }^{12}$ The diagnosis of rhinosporidiosis was confirmed by HPE; no growth was seen on culture. R. Seeberi is in fact a protistan parasite that cannot be cultured. 13

Tubercular granuloma made up for $24(8 \%)$ cases and displayed a clinical pattern, which matched with studies from across the country where lupus vulgaris was the commonest type followed by scrofuloderma and tuberculosis verrucosa cutis; scrofuloderma was the commonest clinical type in some other studies. Mantoux test was found to be positive in 20 (83.33\%) cases; positivity has been reported from 68 to $100 \%$ in various studies.

Out of 24 cases of tubercular granuloma subject to histopathology, 22 (91.67\%) cases showed definite evidence of tubercular granuloma, which is similar to $96 \%$ concordance observed by Acharya et al. and differs from Sharma S et al. who observed in approximately 70.9\%. One of the cases with inconsistent histology had a picture consistent with fungal granuloma. Caseation necrosis was seen in $4(25 \%)$ cases of lupus vulgaris, $1(50 \%)$ case of tuberculosis verrucosa cutis, and $10(100 \%)$ cases of scrofuloderma along with AFB positivity in only one case of scrofuloderma, comparable to a study by Thakur et al. Though demonstration of AFB is very specific for diagnosis, it cannot be detected easily as observed from other studies too.6,14-16

Syphilis constituted 17 (5.67\%) cases. All the cases were reactive with Rapid Plasma Reagin (RPR) test; and tested positive by treponemal tests. Dark-Ground Illumination (DGI) microscopy showed treponema pallidum in 13 (76.47\%) cases. Serological tests form the mainstay in the diagnosis and followup of syphilis. ${ }^{17}$ Moreover, as most patients were reluctant to undergo biopsy, none of the patients presenting with primary and secondary syphilis had been further sent for histopathological confirmation. Two cases were clinically diagnosed as actinomycosis. Gram stain showed gram negative bacilli, HPE confirmed presence of suppurative granulomas with central actinomycotic colonies in one patient. Permi et al. and Mirza $\mathrm{M}$ et al. found similar findings in all their cases, while $100 \%$ concordance was found by Bansal et al.2,6 Patients clinically diagnosed as foreign body and parasitic granulomas showed 100\% clinicopathological concordance in conformity to other studies. 
In these cases, history and clinical background, rather than morphology helped in clinical diagnosis. ${ }^{2}$ Three cases clinically diagnosed as LGV were confirmed through histopathological examination of lymph nodes. Donovanosis clinically amounted to 2 cases; tissue smear and HPE confirmed diagnosis in 1 (50\%). Donovan bodies have been found from $21 \%$ to $75 \%$ in other studies. ${ }^{18}$ both the cases of rhinoscleroma diagnosed clinically showed histopathological confirmation. Section from both cases showed abundance of plasma cells, foamy histiocytic cells, polymorphs and Russell bodies. Histiocytes and plasma cells were seen predominantly in all their cases by Permi and Meyer, while Russell bodies were seen in $40 \%$ and $22.22 \%$ cases respectively. ${ }^{19} \mathrm{~A}$ clinically suspicious case of noduloulcerative lesions was histopathologically confirmed to be granulomatous mycosis fungoides.

Out of the 283 cases who underwent biopsy and histopathological examination, 236 cases showed positive results accounting for $83.39 \%$ clinicopathological concordance, which is similar to studies by authors who have obtained $92 \%, 87.8 \%$ and $88.7 \%$ positivity.2,6,20 But it differed from studies by authors where etiological diagnosis was established in only $22.7 \%$ and $31 \%$ respectively. 4,21 The studies which showed similar findings with ours used similar diagnostic methods in establishing their diagnosis. Studies which differed in their findings were also conducted along similar lines; minor variation was seen in the special stains used. The high percentage of clinicopathological concordance in most studies bears testimony to the fact that time tested technique of biopsy and histopathological evaluation for diagnosis of granulomatous disorders was and still reigns as the gold standard. The absence of concordance in some patients could be attributable to some drawback either with the dermatologist or the pathologist or a communication gap. A thorough clinical evaluation followed by cooperation between the clinician and pathologist is mandatory and is much more relevant in dermatology than in any other discipline of medicine.

Granulomatous lesions encompass a wide plethora of clinical manifestations and an equally robust basket of diagnostic tools. In developing countries, granulomas of infective origin are frequently encountered. Setting too high standards for diagnosis will prove to be exorbitant, burdensome and unfeasible for patients who come from various strata of life and often acquire these pathogens during occupational exposure. Arrival at an early diagnosis becomes mandatory to mitigate the inexorable threat of morbidity and mortality, besides curtailing mental, physical and financial loss. Histopathology remains a time tested tool for establishing a correct diagnosis like in many other diseases pertaining to various organ systems of the body. ${ }^{16}$

But, in the present scenario, integration of newer ancillary tools like immunohistochemistry, in situ hybridization, polymerase chain reaction (PCR) etc. as a diagnostic adjunct to histopathology will definitely provide a solution to the problem of diagnostic ambiguity even further.

\section{ACKNOWLEDGEMENT}

I am very grateful to Dr. Swapna Kakoty, Associate Professor, Department of Community Medicine and Dr. Uddip Talukdar,
Assistant Professor, Department of Psychiatry, FAAMC\&H for their continuous guidance and immense help towards the statistical analysis and editing of this manuscript.

\section{REFERENCES}

1. Kumar V, Abbas A, Aster J. Inflammation and repair. In: Kumar V, Abbas A, Aster J, et al, editors. Robbin's \& cotran pathologic basis of medicine. South Asia ed. Reed Elsevier; 2014;69-111.

2. Permi HS, Shetty JK, Shetty PK, et al. A histopathological study of granulomatous inflammation. NUJHS 2012;2:15-19.

3. Pawale J, Belagatti SL, Naidu V, et al. Histopathological study of cutaneous granuloma. Indian Journal of Public Health Research \& Development 2011;2:74-79.

4. Zafar M Naved Uz, Sadiq S, Memon M Arif. Morphological study of different granulomatous lesions of the skin. J Pak Assoc Derma 2008;18:21-28.

5. Bansal C, Batra M, Sharma KL, et al. Facial granulomatous dermatoses: a clinic-pathological study. Journal of Saudi Society of Dermatology \& Dermatologic Surgery 2013;17:55-61.

6. Bal A, Mohan H, Dhami GP. Infectious granulomatous dermatitis: a clinico pathological study. Indian J Dermatol 2006;51:217-220.

7. Dhar S, Dhar S. Histopathological features of granulomatous skin diseases: an analysis of 22 skin biopsies. Indian J Dermatol 2002;47:88-90.

8. Thakkar S, Patel S. Clinical profile of leprosy patients: a prospective study. Indian J Dermatol 2014;59:158-162.

9. Sharma A, Sharma RK, Goswami KC, et al. Clinicohistological correlation in leprosy. JK Science 2008;10:120-123.

10. Bordoloi P, Nath R, Borgohain M, et al. Subcutaneous mycoses: aetiological study of 15 cases in a tertiary care hospital at Dibrugarh, Assam, northeast India. Mycopathologica 2015;179:425-435.

11. Ribes JA, Vanover-Sams CL, Baker DJ. Zygomycetes in human disease. Clin Microbiol Rev 2000;13:236-301.

12. Verma S, Verma GK, Singh G, et al. Sporotrichosis in subhimalayan India. Plos Negl Trop Dis 2012;6:e1673.

13. Arseculeratne SN. Rhinosporidiosis: what is the cause? Curr Opin Infect Dis 2005;18:113-118.

14. Acharya KM, Ranpara $\mathrm{H}$, Dutta $\mathrm{R}$, et al. A clinicopathological study of 50 cases of cutaneous tuberculosis in Jamnagar District. Indian J Dermatol 1997;63:301-303.

15. Sharma S, Sehgal VN, Bhattacharyya SN, et al. Clinicopathologic spectrum of cutaneous tuberculosis: a retrospective analysis of 165 Indians. Am J Dermatopathol 2015;37:444-450.

16. Thakur BK, Verma S, Hazarika D. A clinicopathological study of cutaneous tuberculosis at Dibrugarh district, Assam. Indian J Dermatol 2012;57:63-65.

17. Ratnam S. The laboratory diagnosis of syphilis. Can J Infect Dis Med Microbiol 2005;16(1):45-51.

18. Rege VL, Sukla P. Profile of genital sores in Goa. Ind J Sex Trans Dis 1993;14:10-14.

19. Meyer PR, Shum TK, Becker TS, et al. Scleroma (Rhinoscleroma) a histologic, immunohisto chemical study with bacteriologic correlates. Arch Pathol Lab Med 1983;107:377-383.

20. Gautam K, Pai RR, Bhat S. Granulomatous lesions of the skin. Journal of Pathology of Nepal 2011;1:81-86.

21. El-Khalawany M, Meerag I, Eassa B, et al. Clinicopathological feature and the practice of diagnosing infectious cutaneous granulomas in Egypt. Int J Infect Dis 2011;15:e620-e626 